This item was submitted to Loughborough's Research Repository by the author.

Items in Figshare are protected by copyright, with all rights reserved, unless otherwise indicated.

\title{
Saving on discounts through accurate sensing - Salespeople's estimations of customer price importance and their effects on negotiation success
}

\section{PLEASE CITE THE PUBLISHED VERSION}

https://doi.org/10.1016/j.jretai.2015.08.002

\section{PUBLISHER}

(c) New York University. Published by Elsevier

VERSION

AM (Accepted Manuscript)

\section{PUBLISHER STATEMENT}

This work is made available according to the conditions of the Creative Commons Attribution-NonCommercialNoDerivatives 4.0 International (CC BY-NC-ND 4.0) licence. Full details of this licence are available at: https://creativecommons.org/licenses/by-nc-nd/4.0/

\section{LICENCE}

CC BY-NC-ND 4.0

\section{REPOSITORY RECORD}

Alavi, Sascha, Jan Wieseke, and Jan H. Guba. 2019. "Saving on Discounts Through Accurate Sensing Salespeople's Estimations of Customer Price Importance and Their Effects on Negotiation Success". figshare. https://hdl.handle.net/2134/33441. 


\title{
Saving on Discounts through Accurate Sensing - Salespeople's Estimations of Customer Price Importance and their Effects on Negotiation Success
}

\begin{abstract}
Discount negotiations are a prevalent phenomenon in retailing and serve as key instruments for adjusting retail prices to the individual customer. Accurately perceiving the importance the customer attaches to price, which the authors label customer price importance (CPI) sensing, should be critical to retail salespeople’s negotiation performance. However, extant research has neither conceptually nor empirically investigated the role of CPI sensing in customer-salesperson interactions. Addressing this research void, this study analyzes both antecedents and consequences of salespeople's accurate CPI sensing in discount negotiations with customers. The authors use a four-sources multi-level data set from the B2C automobile retailing context that comprises data on 537 salesperson-customer interactions. Results provide evidence that through accurate CPI sensing, salespeople are able to reduce the discounts they grant to customers substantially (on average by $\$ 616$ per transaction). Moreover, with respect to CPI sensing accuracy, results show that retail salespeople misperceive CPI owing to reliance on heuristic customer cues.
\end{abstract}

Keywords: retail negotiations; individual pricing; perceptual accuracy; price importance; negotiation performance 


\section{Introduction}

The pricing policy constitutes one of the most powerful tools of retailers to increase profits (Levy et al. 2004; Gauri, Trivedi, and Grewal 2008). An important goal of retailers’ pricing policy is to charge prices which maximize their margins while maintaining their customers' purchase intention (Kopalle et al. 2009; Simon and Dolan 1996). Therefore, retailers try to customize prices that match their individual customers’ willingness to pay (Grewal et al. 2011; Johnson, Tellis, and Ip 2013). One approach for retailers to individualize selling prices is to allow customers to negotiate for discounts (Clopton 1984; Nagle and Holden 1995). Discount negotiations are a prevalent phenomenon in major U.S. retail industries such as jewelry (\$33 billion in revenues in 2013), furniture ( $\$ 53$ billion), or automobile wholesaling ( $\$ 489$ billion) (Marks 2013; IBISWorld Industry Information 2014). Every second customer in the US negotiates for a better deal on his or her purchases in the retailing context (Marks 2013).

To successfully negotiate discounts which satisfy their customers yet are simultaneously profitable from their company’s perspective, salespeople should understand their customers’ preferences (Murnighan et al. 1999). A particularly relevant customer preference which salespeople should address in their sales strategy in order to negotiate optimal discounts should be the customers' specific price importance (CPI) (Wakefield and Inman 2003). In our study, we refer to CPI as the relevance of price for the customer's purchase decision compared to other (benefit-related) product attributes. By investigating the importance of price relative to other product attributes we reflect findings of behavioral pricing research that customers evaluate the price of a product in relation to its value or benefits (Hamilton and Srivastava 2008; Zeithaml 1984). The relative nature of CPI is the major difference to related concepts like price-sensitivity or reservation price. Understanding the relative importance of price helps retail salespeople in negotiations to adjust their sales strategy to the individual customer by focusing either on monetary or non-monetary benefits. 
Despite the strong relevance of discount negotiations for retailers’ profitability, many sales managers are dissatisfied with their sales force's current performance in the realm of price enforcement. Nearly $40 \%$ of sales executives state that salespeople’s capability to avoid discounting needs improvement (CSO Insights 2011). Interestingly, 35 years ago Stephenson, Cron, and Frazier (1979) suggested that in negotiations, salespeople are either not motivated to or capable of setting prices corresponding to the maximum the customer is willing to pay. While several studies have analyzed the effect of incentive systems on salespeople's motivation to make profitable pricing decisions (Dalrymple, Stephenson, and Cron 1981; Frenzen et al. 2010), the question of whether salespeople are capable of negotiating prices which correspond to their customers' willingness to pay in discount negotiations has not been addressed to date (please refer to Figure 1). A key success factor of individualized pricing should be the salesperson's ability to acquire accurate CPI information. We refer to the process of acquiring this CPI information during the interaction as CPI sensing.

---- Insert Figure 1 about here ----

In order to further explore the practical relevance of CPI sensing, we employed the market research agency usamp to conduct a cross-industry survey of 100 US sales managers from several retail industries on the issue of acquiring CPI information. The survey revealed that $68 \%$ of the sales managers consider CPI sensing to be a very important salesperson ability (31\% consider it to be important, and only $1 \%$ to be not important).

Despite its considerable practical relevance for retailing, extant academic works did not investigate the role of CPI sensing in customer-salesperson negotiations. Neither retailing research nor negotiation research contribute to an understanding of the process of acquiring and using CPI information in customer-salesperson interactions, making CPI sensing a novel and important concept. Thus, examining CPI sensing may significantly extend research on price discrimination in retailing (Grewal et al. 2011; Xia, Kukar-Kinney, and Monroe 2010) by examining salespeople’s capability of negotiating profitable discounts. Regarding research on 
the delegation of pricing authority to the salesforce (e.g., Frenzen et al. 2010; Stephenson, Cron, and Frazier 1979) the introduction of CPI sensing challenges the critical assumption inherent in this research stream-that salespeople automatically possess CPI information that is superior to that of their management. For the field of negotiation research our study provides further evidence for the effectiveness of gathering customer information in price negotiations (De Dreu and Van Kleef 2004; Puccinelli et al. 2009) and indicates that CPI sensing is a key success factor that should be considered in future negotiation research.

In our study, we provide a comprehensive account of CPI sensing. We seek to answer three key research questions: (1) Does CPI sensing accuracy improve negotiation performance in a retail context? (2) What are the contingency factors of CPI sensing accuracy effectiveness? (3) Which factors affect the accuracy of a salesperson's CPI sensing? To answer these research questions, we conducted an empirical investigation in the $\mathrm{B} 2 \mathrm{C}$ automobile retailing context. We examined a sample of 537 real-life salesperson-customer interactions and data gathered from four independent sources.

Our results show that CPI sensing accuracy essentially improves salespeople’s negotiation performance and that this effect is increased by high revenue goal importance for the salesperson Specifically, accurate CPI sensing helps salespeople to grant on average $1.96 \%$ lesser discount (6.57\% compared to 8.53\%) while maintaining the customers’ purchase intention. Another key finding of our study is that salespeople’s CPI assessments are distorted by reliance on cognitive heuristics. In building CPI perceptions, salespeople make use of heuristic customer-specific cues (customer age, customer product knowledge, and customersalesperson relationship length) which distort their perceptions. For example, by relying on customer age, salespeople underestimate CPI on average by $14 \%$.Beyond its theoretical contributions, our study holds several implications for retailing practice. By identifying accurate CPI information as a highly effective characteristic for segmenting customers and 
setting individual prices, we provide retailing practitioners with a powerful means for adjusting their pricing policy to the market, as CPI sensing accuracy has a strong impact on profit.

\section{Conceptual Framework}

The central construct of our conceptual framework is CPI sensing accuracy—defined as the degree to which the salesperson correctly perceives CPI ( please refer to Figure 2 for an overview of the conceptual framework). CPI sensing refers to the salesperson's perception formation of how much importance a customer attaches to price relative to other product attributes, thereby constituting a social perception. Therefore, in what follows, we develop our conceptual framework from prior literature on social cognition theory (e.g., Chaiken and Trope 1999; Kelley 2013; Swann 1984). We hypothesize not only the effects of CPI sensing accuracy on negotiation outcomes but also CPI sensing accuracy antecedents. Below, we elaborate on the parts of our conceptual framework in further detail.

Does CPI sensing accuracy improve negotiation performance in a retail context? Outcomes of CPI sensing accuracy. In social interactions, individuals form perceptions about their counterparts in order to attain their interaction goals (Kelley 2013; Swann 1984). These perceptions help people predict their counterparts’ behavior and adapt their own behavior appropriately (Swann 1984). In retail price negotiations, we argue that salespeople need to form accurate perceptions of CPI in order to deploy accurate sales strategies to achieve a key negotiation goal: to negotiate the least possible discount which is still acceptable for the customer (Huber and Neale 1987). This goal implies that two negotiation outcomes of CPI sensing accuracy have to be considered: First, the negotiated discount, and second, the likelihood of an agreement, i.e., the customer's purchase intention. Reflecting these two goals, we include negotiated discount and customers' purchase intention in the model. To capture that the negotiated discount may influence customers’ purchase intention, we specify the respective 
effect in the model. Furthermore, including purchase intention allows us to capture the likelihood of a later agreement, if the customer delays the final purchase decision.

What are the contingency factors of CPI sensing accuracy effectiveness? Moderators of the CPI sensing accuracy-performance link. As prior negotiation research provides clear evidence for the highly contingent nature of negotiation behavior (e.g., Stuhlmacher and Champagne 2000), we include moderators into our conceptual model. Specifically, we incorporate moderators to clarify the conditions under which CPI sensing accuracy affects negotiation outcomes. For the effect of CPI sensing accuracy on negotiated discount, we suggest that the salesperson's revenue goal importance should represent a key moderator. Prior research has established that task-related goals increase salespeople's motivation to spend more effort on their work (Fu, Richards and Jones 2009). Thus, revenue goal importance should raise the salesperson's motivation to actually use the acquired knowledge. With respect to the effect of CPI sensing accuracy on purchase intention, we suggest that, rather than a direct effect, an interaction effect occurs of CPI sensing accuracy and the salesperson's customer orientation. Customer orientation is considered one of the most important factors that drives retail salespeople’s success (Goff et al. 1997; Saxe and Weitz 1982) and should indicate whether the salesperson utilizes CPI information in a customer-friendly manner or not. If the salesperson only focuses on negotiating the least possible discount without having the customer's interests and needs in mind, a detrimental effect of CPI sensing accuracy on purchase intention is likely.

Which factors affect a salesperson's CPI sensing accuracy? Antecedents of CPI sensing accuracy. When forming perceptions in social interactions perceivers use various cues to infer a target's traits (e.g., Borkenau and Liebler 1992; Brunswik 1955). These cues may be either valid if they correlate with the actual traits they should predict, or invalid if there is no correlation (Zebrowitz and Collins 1997). In this respect, the dual-process model of impression formation (Brewer 1988; Chaiken and Trope 1999) posits that individuals form perceptions either heuristically or analytically. Particularly in sales or negotiation encounters, when it 
comes to first impressions (Hall, Ahearne, and Sujan 2015) and time restrictions are likely (De Dreu 2003) salespeople frequently rely on heuristic processing and only consider a very limited set of cues (Szymanski and Churchill 1990). This increases the likelihood of stereotyping and misperceptions (De Dreu 2003) and promotes the utilization of rather invalid cues. Our study aims at identifying invalid heuristic cues which lead salespeople to misperceive CPI.

Therefore, we included three potential cues into our framework on which salespeople may rely when heuristically processing customer information: the customer's age, the customer's product knowledge and the salesperson-customer relationship length. Age is suggested to be one of the first and most important cues individuals take into account when forming social perceptions (Cuddy and Fiske 2002). Customer product knowledge should be easily observable to a salesperson and may provide an important heuristic indicator regarding the distribution of power in the negotiation (De Dreu and van Kleef 2004). Eventually, relationship length should be an available cue the salesperson may utilize to infer the customer's attitude towards the interaction (Wieseke, Alavi, and Habel 2014). ${ }^{1}$

---- Insert Figure 2 about here ----

\section{Hypotheses Development}

As our primary research question addresses whether CPI sensing accuracy improves negotiation performance, we first present our argumentation on CPI sensing accuracy outcomes. We then derive hypotheses regarding CPI sensing accuracy antecedents.

\section{Consequences of CPI Sensing Accuracy for Negotiation Outcomes}

In what follows, we derive the hypothesis for the effect of CPI sensing accuracy on negotiated discount. On the basis of social cognition research (Swann 1984) and findings from personal

\footnotetext{
${ }^{1}$ We acknowledge that there may be further potential heuristic CPI sensing cues. However, in order to keep the study concise, we refrained from including additional cues. Particularly gender and race have been discussed in prior literature as important sources of stereotypes. Unfortunately, both cues did not fit the sample's context. In automobile retailing gender stereotypes constitute a prevalent, yet also very idiosyncratic issue (Ayres and Siegelman 1995) and race stereotypes are much less relevant in the European market as compared to the US.
} 
selling and negotiation research (e.g., Spiro and Weitz 1990; Hüffmeier et al. 2014), we suggest that CPI sensing accuracy enables the salesperson to tailor the sales strategy to the individual customer's needs and thereby decreases the necessity of granting discounts. Accurate CPI sensing should provide the salesperson with valuable information regarding the relevance of price for the customer's purchase decision compared to other product attributes. High CPI should indicate that the customer is highly focused on the product's price and is primarily interested in minimizing the costs of the product. Low CPI, in turn, should indicate that other product attributes are more important and that the customer is more interested in non-monetary benefits of the product (such as quality or usability). This notion aligns with findings from Wieseke, Alavi, and Habel (2014) who differentiate customers with a price focus from customers with a quality focus and demonstrate that these customers substantially differ in their negotiation behavior.

In line with adaptive selling research (Spiro and Weitz 1990), this information should help the salesperson to adapt his or her sales strategy to the individual customer's preferences. If price is more important for the customer the sales strategy should focus on price-related aspects — every benefit of the product should be illustrated in terms of the costs the customer might save (e.g., a low mileage) or the monetary value a certain feature has (e.g., the price of a radio). If other attributes are more important than price the communication should focus on the (non-monetary) benefits of the product.

Thus, ideally, a salesperson facing a customer with high CPI will address the customer's price focus in the selling presentation. Being aware that the customer attaches high importance to price, the salesperson would stress the monetary value of the product attributes (like e.g., the regular price of a radio in the car). Conversely, if the customer has low CPI the salesperson would employ a different strategy and put more effort into presenting the product in terms of non-monetary benefits, like for example the security to have a reliable product or social value stemming from image effects. To this effect, the salesperson's exhibition of an 
appropriate sales strategy strongly depends on the salesperson's CPI sensing accuracy since inaccurate perceptions would induce the salesperson to employ a less effective and maybe even detrimental sales strategy which does not take the customer's preferences into account. With an appropriate sales strategy the salesperson should have to grant the customer significantly lesser discount than with an inappropriate sales strategy (see Figure 3).

---- Insert Figure 3 about here ----

In conclusion, this means that in both cases—-for customers with high or low CPI—CPI sensing accuracy is highly relevant for the salesperson's choice of sales strategy. Although a high price-focus in the salesperson's argumentation strategy is required for customers with high CPI, it may have detrimental effects for customers who are initially not focused on price. In conclusion, accurate CPI sensing helps salespeople to choose an argumentation strategy that addresses the customer's individual preferences in the best possible manner, and as a result CPI sensing accuracy is positively related to economic negotiation success. Therefore, we hypothesize:

$\mathrm{H}_{1}$ : The higher a salesperson's CPI sensing accuracy, the lesser the negotiated discount in a price negotiation with a customer.

\section{Moderators for the CPI Sensing Accuracy-Negotiation Outcome Link}

In the following, we develop the hypothesis for the interaction effect between CPI sensing accuracy and revenue goal importance and subsequently elaborate on the CPI sensing accuracy-customer orientation interaction. We suggest that revenue goal importance amplifies the effect of CPI sensing accuracy on the negotiated discount because it provides the salesperson with a stronger motivation to use the information acquired through CPI sensing.

Revenue goal importance. We define this construct as the perceived urge of salespeople to meet their revenue goals. Salespeople commonly have to meet such goals to obtain contingent bonuses (John and Weitz 1989). Agency theory (Eisenhardt 1989) proposes that revenue goals should have positive effects on sales performance and the positive effects of 
goals on performance have also been confirmed in negotiation research (e.g., Huber and Neale 1987; Zetik and Stuhlmacher 2002). These effects can be explained by an increase in motivation to close the gap between goals and actual performance (Campion and Lord 1982; Hollenbeck and Williams 1987). To close this gap, salespeople should use resources that are instrumental to their performance more efficiently. The CPI information acquired with help of CPI sensing represents such a resource.

Thus, salespeople with high revenue goal importance should be strongly motivated to leverage the potential of CPI information to increase negotiation performance. This leveraging implies that goal-oriented salespeople may more carefully adapt their argumentation strategy to the individual customer and thereby negotiate lesser discounts. Hence:

$\mathrm{H}_{2}$ : The higher the salesperson's revenue goal importance, the stronger the negative effect of CPI sensing accuracy on negotiated discount.

Customer orientation. We suggest that customer orientation combined with a high level of CPI sensing proficiency should help to alleviate a common problem negotiators face-the so-called negotiator's dilemma (Lax and Sebenius 1986; Hüffmeier et al. 2014). This dilemma refers to the effect that claiming value for oneself during a negotiation typically increases individual outcomes but simultaneously decreases the likelihood of an agreement and may damage the relationship. However, we do not assume CPI sensing accuracy to have this negative effect on purchase intention.

Since with help of CPI sensing the salesperson acquires valuable information on the customer's preferences he or she should be able to estimate more precisely whether a certain level of discount is necessary to close the deal with the customer and thus avoid a negative impact of CPI sensing accuracy on purchase intention. A positive effect on purchase intention, however, should be very unlikely as well, as accurate CPI sensing is used by the salesperson to grant a lesser discount to the customer and hence reduces his or her economic value from the 
transaction. As both, a positive as well as a negative effect, should be unlikely, we do not hypothesize a direct effect of CPI sensing accuracy on purchase intention.

However, CPI sensing accuracy should be related to customers’ purchase decision if it is combined with customer orientation. Customer orientation refers to the degree to which salespeople try to help their customers to satisfy their needs (Saxe and Weitz 1982) and therefore reflects whether the salesperson uses CPI information with the customer's best interest in mind or only with his or her own interests in mind. A customer-oriented salesperson should show the customer that he or she is understood and address the customer's needs in the selling presentation.

Accurate CPI information combined with customer orientation enables the salesperson to make small concessions at the right moment to display good will and should prevent an adverse effect of CPI sensing accuracy on the customer's purchase intention (Fisher and Ury 1981). Whereas a salesperson low on customer orientation might merely use CPI information to avoid concessions which do not increase the customer's perceived value of the product, a customer-oriented salesperson might additionally make small concessions regarding issues the customer values (Thompson and Hastie 1990). Thus, the more accurate the CPI perception and the more customer-oriented the salesperson the more satisfied the customer should be with the interaction. In contrast, a salesperson with low customer orientation may not be highly sensitive to the customer's interests. The salesperson should mainly focus on negotiating the least possible discount, taking a positional bargaining approach (Fisher and Ury 1981), and therefore use CPI information to get as close as possible to the customer's limit. However, this adversarial negotiation approach may lead the customer to feel misunderstood or exploited, which should afflict purchase intention. Thus, we hypothesize:

$\mathrm{H}_{3}$ : Customer orientation moderates the effect of CPI sensing accuracy on purchase intention. Specifically, if the salesperson has a low customer orientation, CPI sensing accuracy negatively influences purchase intention. 


\section{Antecedents of CPI Sensing Accuracy}

Having hypothesized the effects of CPI sensing accuracy on negotiation outcomes, we now address antecedents for CPI sensing accuracy. We derive hypotheses regarding three potential heuristic cues and their potential effects on CPI sensing accuracy. These are customer age, customer product knowledge and the salesperson-customer relationship length.

Customer age. Age is a demographic criterion frequently used for customer segmentation (Holbrook and Schindler 1996) and is also mentioned as a key indicator for customer categorization in sales interactions (e.g., Szymanski 1988). Cuddy and Fiske (2002) even state that "in first encounters, age is one of the earliest characteristics we notice about other people" (Cuddy and Fiske 2002, p.3).

Being such an important cue in social interactions, it seems likely that salespeople rely on customer age when forming CPI perceptions based on heuristic processing. This view is supported by research on age-related stereotypes, suggesting that older people are usually perceived as being less competitive (e.g., Haefner 1977) and less dominant (Montepare and Zebrowitz-McArthur 1988). Salespeople who harbor these stereotypes in discount negotiations may heuristically infer older customers to be low on CPI, since a high importance of price is usually accompanied by a more competitive and dominant negotiation behavior (Brett, Pinkley, and Jackofsky 1996).

Importantly, however, the inferences developed above are based on age-related stereotypes. Since stereotypes are often overgeneralized and exaggerated and may reflect a biased reality (Wieseke et al. 2012) these inferences do not have to reflect actual age differences in CPI. More precisely, salespeople who harbor these stereotypes and rely on heuristic processing may overgeneralize their perception that older people are less competitive and therefore systematically underestimate CPI of older people. Considering that salespeople’s CPI assessments may be biased by overgeneralizations through age-related stereotypes, we hypothesize: 
$\mathrm{H}_{4}$ : The higher the customer's age, the greater the salesperson's underestimation of CPI.

Customer product knowledge. Customers with sophisticated product knowledge are usually more involved with the product than customers with a lower knowledge level (Park and Moon 2003). Highly involved customers should be better informed about product characteristics, alternatives in the market, and particularly about prices (Park and Moon 2003). Furthermore, prior research has frequently mentioned expertise as a source of power in negotiations (e.g., De Dreu and Van Kleef 2004; French and Raven 1959). Therefore, when relying on heuristic processing salespeople might perceive knowledgeable customers to be more threatening regarding the economic negotiation outcome (negotiated discount) and believe that they put a higher emphasis on the selling price.

However, we suggest this interpretation to be distorted by a negativity bias (Rozin and Royzman 2001). This perceptual bias describes the tendency of individuals to put more weight on negative than on positive information. In line with research on this bias we suggest salespeople to put more weight on the negative interpretation outlined above (i.e., the customer is knowledgeable of price levels which increases his or her CPI and thus, it is more difficult to achieve a good negotiation outcome) than on a different potential positive interpretation which we explain below. That is, the perceptual heuristic that highly knowledgeable customers are more sensitive to price omits that customers with a high product knowledge also value product quality differently than less involved customers. Because of their high involvement, they develop a more sophisticated understanding of the product's attributes and value and thus might accept higher prices (Lichtenstein, Bloch, and Black 1988). This view is supported by Rao and Sieben (1992) who find that in fact knowledgeable customers have a higher willingness to pay than customers with low product knowledge. 
In conclusion, we suggest that salespeople fall prey to a negativity bias and interpret customer product knowledge in a threatening sense, inducing them to overestimate CPI for knowledgeable customers. Thus, we hypothesize:

$\mathrm{H}_{5}$ : The better the customer's product knowledge, the higher the salesperson's overestimation of CPI.

Relationship length. There are plausible reasons for salespeople to assume that loyal customers whom they have known for many years attach less importance to price. The salesperson is more likely to attribute the customer's loyalty to the good relationship than to economic motives, falling prey to self-serving interpretations (e.g., Campbell and Sedikides 1999). In this case, the salesperson would expect the customer to be less focused on price because the customer would not want to harm the relationship by making high demands (Jap, Robertson, and Hamilton 2011). This view is promoted by practice literature (Nagle and Holden 1995), where loyal customers are often characterized as being more relationshiporiented than price-oriented.

Particularly when salespeople engage in heuristic rather than analytical processing (Chaiken and Trope 1999) they are likely to interpret customer loyalty in the way developed above, because this interpretation is self-serving (e.g., Campbell and Sedikides 1999). However, if they do so, they overlook the possibility that customers' loyalty could lead to even higher CPI. A recent study by Wieseke, Alavi, and Habel (2014) supports this view. They demonstrate that even though loyal customers are less price-sensitive, they attach much more importance to price in discount negotiations than new customers. The rationale for these findings is that customers might become accustomed to receiving discounts. Additionally, with increasing relationship length customers may expect to be rewarded for their loyalty to the company in terms of greater discounts and may perceive a higher negotiation power (Wieseke, Alavi, and Habel 2014). 
In conclusion, the self-serving interpretation of salespeople that loyal customers attach less importance to price should be misleading. Thus, if salespeople rely on this cue and infer that relationship length decreases CPI, they will systematically underestimate CPI. Therefore, we hypothesize:

$\mathrm{H}_{6}$ : The longer the relationship with the customer, the greater the salesperson's underestimation of CPI.

\section{Method}

Below, we describe our data collection method and sample characteristics and then specify our measures and the analytical approach we used to analyze the data.

\section{Data Collection and Sample}

Data requirements. Particularly in negotiation research, investigators have raised concerns regarding the generalizability of results obtained in laboratory settings (Evans and Beltramini 1987; Zetik and Stuhlmacher 2002). We therefore decided to conduct our study in the field. However, this approach required extensive effort from our research team. First, we had to find a context where prices are negotiated regularly. Second, to measure perceptual accuracy in social interactions, we needed at least two data sources - the target (customer) and the perceiver (salesperson)—making a dyadic approach necessary. Third, as customer perceptions may be biased in some cases, we employed observers to validate customers' answers and also validated the discount measure by referring to objective company records.

Sample description. To fulfill the requirements set out above, we collected dyadic data from salesperson-customer interactions in a B2C car retailing setting (28 different dealerships). We chose the context of the automobile retailing industry because discount negotiations regularly occur when customers purchase cars. To make our sample as balanced as possible, we cooperated with car dealership chains that were situated in 11 different cities and that offered new and used cars of 5 different brands. 
Each salesperson completed a questionnaire providing general perceptions and attitudes concerning his or her job. Additionally, we obtained data from salespeople and their customers after sales conversations with the help of questionnaires, which our research team personally administered to salespeople and customers to achieve the best possible response rates and to ensure accurate matching. The questionnaires referred to the one specific car which was the major subject of the sales interaction. Since customers entered the sales interactions with very clear preferences regarding the feature set of the car the subject of the interaction did not shift from one to another car. In the majority of interactions salesperson and customer initially specified the features of the car and then negotiated the price based on a fixed feature configuration with a fixed feature set.

Customers and salespeople were matched by using code numbers. After about 30 weeks of data collection (we spent an average time of one week per dealership), we had obtained 537 salesperson-customer interactions. In this process, 171 salespeople and 537 customers were surveyed, with a mean of 3.16 interactions recorded per salesperson, ranging between one and 10 interactions. The response rate for salespeople was 100\%, as participation was obligatory, and the response rate for customers was about 45\%. The average age of salespeople was 37.68 years with a median of 38 and a standard deviation of 10.69, and the average job experience was 12.87 years $(\mathrm{SD}=9.79)$, ranging between 0 and 44 years. The customers had a mean age of 44.7 with a median of $44(\mathrm{SD}=14.69)$.

In order to avoid biasing the results by only observing successful sales interactions we collected data both on discount negotiations which were closed with a sale (45\% of the interactions) and interactions where no agreement was reached (55\% of the interactions). However, all interactions ended with a final sales price the salesperson offered to the customer. We asked the customer for his or her purchase intention (i.e., how likely a later purchase was) in order to reflect whether there was disagreement on the sales price or whether the purchase decision was only delayed. 
Selection bias check. In our field study design, customers who participated in our study could have systematically varied from customers who declined to participate. Thus, to check whether such a selection bias might confound the results of the data analysis, we inspected whether responses from participants systematically differed from responses of non-participants. Using special incentives (free car wash vouchers) and a very short version of the questionnaire, we collected data from customers who originally did not intend to participate. We then compared responses from participants with responses from non-participants with regard to critical customer variables (CPI, negotiated discount, age, and relationship length) using a MANOVA approach. The results show that the groups do not differ systematically regarding these variables. Thus, a selection bias is unlikely to be an issue for the sample.

\section{Measures}

The Appendix provides a full list of items employed in this study, including the results of the confirmatory factor analysis. Below, we focus on discussing the measures of the core constructs.

For the CPI sensing accuracy measure, we followed prior research on perceptual accuracy (Gill and Swann 2004) and employed a dual-perspective approach to measure the construct. The basic notion of our CPI sensing accuracy measurement is to compare the salesperson's rating of CPI and the factual CPI indicated by the customer. If the salesperson's rating of CPI closely matches the customer's factual CPI, the salesperson's CPI sensing accuracy is high. Conversely, if the salesperson's rating of CPI strongly deviates from the customer's factual CPI, the salesperson's CPI sensing accuracy is low. Therefore, we calculated an absolute difference score of salesperson and customer CPI ratings to test our hypotheses relating to negotiation outcomes.

To measure CPI, we used a ranking-based measurement approach. This measurement approach allowed us to consider that customers tend to evaluate the price of a product in 
relation to its benefits or value (e.g. Hamilton and Srivastava 2008; Zeithaml 1984). By utilizing a ranking scale we could furthermore improve response validity and reduce the likelihood of demand effects by inducing customers to mentally trade-off alternatives (e.g. McCloy, Heggestad, and Reeve 2005). Both the salesperson and the customer completed a scale adapted from Homburg, Wieseke, and Bornemann (2009). Customers ranked price among five other shopping-related needs with regard to its importance for the buying decision. After each sales interaction, the salesperson was asked to indicate on the same scale the ranking of the respective customer's shopping needs. To ensure that higher values reflect higher CPI, we reverse-coded the scale by subtracting the ratings from 7.

Ranking measures are afflicted with the methodological problem that they are ordinal in nature and do not reflect weights of the ranking position. For instance, a customer might rank price second, but allocate a very low weight to it, as the first product attribute is by far the most important one. In this case there would be a long cognitive distance between the ranking positions 1 and 2 and a very small distance between the other ranks. If this was true in our data, the data pattern should reveal a non-linear relationship between CPI measured by a rating-scale and our ranking-based measure for customer price importance. However, results of a robustness-check show a linear relationship indicating that the distances between the ranking positions are very similar on average in our data.

To measure negotiated discount, we asked customers to rate the received discount on the car's sticker price in percent. Because objective data were not available for all interactions, the negotiated discount was quoted by the customer. This measure was validated with the help of a correlation analysis between customer quotes and company records $(\mathrm{r}=.712, \mathrm{n}=33, \mathrm{p}<$ $.01)$ and customer quotes and observer data $(\mathrm{r}=.802, \mathrm{n}=119, \mathrm{p}<.01)$.

Measurement reliability. With regard to reliability statistics, all values for Cronbach’s alpha, composite reliability (CR), and average variance extracted for all measurement scales meet or exceed recommended thresholds (Bagozzi and Yi 1988), indicating sufficient 
reliability and convergent validity (the AVE for revenue goal importance is .48 and thereby slightly below the threshold of .5. As Cronbach’s Alpha and CR exceed the recommended values we refrained from excluding an item). We assessed discriminant validity using the criterion of Fornell and Larcker (1981). All constructs passed this test.

\section{Analytical Approach}

The data structure of the study comprises two levels - the interaction level of the sales encounter and the salesperson level. Therefore, we conducted our analysis using multi-level path analyses, which take into account that individuals within a particular group may be more similar to each other than to individuals in other groups (Hofmann 1997). We split our analysis into two parts. First, we examined the effect of CPI sensing accuracy on negotiation outcomes $\left(\mathrm{H}_{1-3}\right)$ and then we tested the effects of different heuristic cues on CPI sensing accuracy $\left(\mathrm{H}_{4-6}\right)$.

Analysis of CPI sensing accuracy consequences $\left(H_{1-3}\right)$. To examine the consequences of CPI sensing accuracy, we conducted a multilevel path analysis (Cohen et al. 2003). Since, $\mathrm{H}_{1}$ suggests CPI sensing accuracy to decrease the negotiated discount regardless of whether the salesperson under- or overestimates CPI, we employed an absolute difference score measure of CPI sensing accuracy. For this purpose, we subtracted the customer's rating from the salesperson's rating and calculated the absolute value.

Assessment of CPI Sensing Directionality. As methodological problems can arise with the use of an absolute difference score as independent variable in structural equation modeling, we conducted two additional analyses to check whether these problems might potentially bias our results. First, one of the most important problems pertains to the fact that absolute difference scores are "directionless measures of congruence, since they treat positive and negative scores the same" (Edwards 1994, p. 60). Even though we expect that the direction of CPI misperception should not matter in our context and analysis, we conducted a test recommended by prior research (Vosgerau, Anderson, and Ross 2008) in order to see whether 
this assumption holds true. We included a variable into our model, which was -1 for an underestimation of CPI by the salesperson, 0 for an accurate assessment and 1 for an overestimation. Then, we included the interaction term of this direction variable and the absolute difference score measure of CPI sensing into the model to assess whether a significant impact on the negotiated discount emerged. Results showed that neither the direction variable itself $(\mathrm{b}=.30, \mathrm{SE}=.52$, n.s. $)$ nor the interaction term with CPI sensing accuracy $(\mathrm{b}=.36, \mathrm{SE}=$ .46) have a significant effect on negotiated discount, indicating that the direction of the misperception did not matter for our analysis.

Second, we conducted a similar test to check whether the effect of CPI sensing accuracy differed between high and low CPI conditions, as this information is not considered when using an absolute difference score measure as independent variable (Edwards 1994). Therefore, we included an interaction term of CPI and the absolute CPI sensing accuracy measure into the model. However, the effect was nonsignificant indicating that the effect of CPI sensing on discount does not depend on the CPI level $(b=-.27, \mathrm{SE}=.28$, n.s.). Thus, we conclude that our approach to utilize an absolute difference measure of CPI sensing accuracy is appropriate for our data.

We conducted the analysis of hypotheses 1-3 in two steps. First, we estimated our model without interaction terms in order to test $\mathrm{H}_{1}$ and then in a second step we included the interaction terms of CPI and revenue goal importance and customer orientation in order to test $\mathrm{H}_{2}$ and $\mathrm{H}_{3}$. As $\mathrm{H}_{2}$ predicts a cross-level interaction between CPI sensing accuracy and revenue goal importance, following Hox (2010), we included a random slope into our model, which captured the effect of CPI sensing accuracy on negotiated discount.

Analysis of CPI sensing antecedents $\left(\mathrm{H}_{4-6}\right)$. The goal of the second analysis was to identify cues salespeople take into account in assessing CPI and whether these cues lead to over- or underestimation of CPI. In order to answer this research question we followed a different approach than in our first analysis. We followed Edwards' suggestion that 
“conceptually distinct constructs [in our case, CPI and the salesperson’s assessment of CPI] should remain distinct in data analysis” (Edwards 1995, p. 310). Thus, we simultaneously tested the effects of all three independent variables on the salesperson's and customer's CPI rating which constitute the components of CPI sensing accuracy (Colbert et al. 2008). This procedure had an important advantage regarding managerial implications of the study since we were able to test whether the respective CPI sensing cues lead to overestimation of CPI or to underestimation. Thus, an overestimation of CPI by the salesperson was indicated by a more positive effect of a specific cue on the salesperson's rating compared to the customer's rating. Conversely, an underestimation was indicated by a more negative effect of a specific cue on the salesperson's rating compared to the customer's rating. To test whether the over- or underestimation was significant, we conducted a further analysis with the raw difference score of CPI sensing accuracy (salesperson’s rating - customer’s rating) as dependent variable. A negative effect for a specific cue in this analysis indicates a significant underestimation, whereas a positive effect indicates a significant overestimation (Edwards 1995).

Control variables. Beyond the hypothesized effects, we controlled for factors that were not included in the hypotheses. Since the negotiation outcomes may be influenced by interaction-specific constraints (Thompson 1990), we controlled for the encounter length and the product price level when testing $\mathrm{H}_{1-3}$. Furthermore, we controlled for the link between negotiated discount and purchase intention since the customer's purchase intention may depend on the granted discount (Lax and Sebenius 1986). Thereby, we were able to test for a potential indirect effect of CPI sensing accuracy on purchase intention via negotiated discount. Eventually, we included an indicator for the direction of the salesperson's misperception (overor underestimation) into the model, to control for potential directionality effects.

In addition to the hypothesized antecedents of CPI sensing $\left(\mathrm{H}_{4-6}\right)$, we included encounter length and the salesperson's job experience. Both variables may impact CPI sensing accuracy, since experienced salespeople may have better sensing skills (Szymanski 1988) and 
the longer a sales interview takes, the more time has the salesperson to make an accurate assessment. Before we conducted the analyses all independent variables were standardized.

\section{Results}

\section{Results for CPI Sensing Accuracy Outcomes}

All analyses were conducted using the statistical software MPlus 7.0 (Muthén and Muthén 2012). Table 1 presents the correlations, means and standard deviations of the constructs. The results for the analysis of CPI sensing accuracy consequences $\left(\mathrm{H}_{1-3}\right)$ appear in Table 2 . Results provide support for $\mathrm{H}_{1}$, indicating that CPI sensing accuracy significantly reduces negotiated discount $(\mathrm{b}=-.96, \mathrm{SE}=.48, \mathrm{p}<.05)$. Moreover, the negative effect of CPI sensing accuracy on negotiated discount is enhanced by revenue goal importance $\left(\mathrm{H}_{2}: \mathrm{b}=-.73, \mathrm{SE}=.41, \mathrm{p}<.05\right)$, which corroborates $\mathrm{H}_{2}$. Figure 4 shows the interaction effect.

---- Insert Table 1 about here ----

---- Insert Table 2 about here ----

---- Insert Figure 4 about here ----

We also find evidence that CPI sensing accuracy has no main effect on purchase intention ( $\mathrm{b}=-.10, \mathrm{SE}=.08$, n.s.). Neither is there an indirect effect via negotiated discount, since the effect of negotiated discount on purchase intention is not significant $(b=.00, \mathrm{SE}=$ .02, n.s.). However, results reveal a significant interaction effect between salesperson’s customer orientation and CPI sensing accuracy $(b=.11, \mathrm{SE}=.04, \mathrm{p}<.01)$, which supports $\mathrm{H}_{3}$. Figure 4 illustrates that CPI sensing accuracy only has detrimental effects on purchase intention for salespeople with low customer orientation (simple slope effect: $b=-.24$, SE $=.10$, $\mathrm{p}<.01)$. For highly customer-oriented salespeople, the effect has a positive sign, but is not significant $(\mathrm{b}=.02, \mathrm{SE}=.08$, n.s.). Additionally, we conducted a robustness check by testing the model without controls. All hypothesized effects remained significant and consistent. 
Taken together, these results indicate that CPI sensing accuracy has the hypothesized effects on negotiation outcomes.

\section{Results for CPI Sensing Accuracy Antecedents}

Results for the analysis of CPI sensing accuracy antecedents $\left(\mathrm{H}_{4-6}\right)$ are displayed in Table 3. Overall, our results provide support for the notion that salespeople make use of cognitive heuristics to form CPI perceptions and that relying on certain cues induces CPI misperceptions. In $\mathrm{H}_{4}$ we hypothesized that customer age induces salespeople to underestimate CPI. Our findings support this hypothesis since customer age has a significant negative effect on CPI sensing accuracy $\left(\mathrm{H}_{4}: \mathrm{b}=-.02, \mathrm{SE}=.01, \mathrm{p}<.01\right)$. The same holds true for $\mathrm{H}_{6}$ regarding relationship length $\left(\mathrm{H}_{6}: \mathrm{b}=-.06, \mathrm{SE}=.03, \mathrm{p}<.05\right)$. Both cues lead to significant underestimations of CPI. Furthermore, we find support for the effect of the customer's product knowledge on CPI sensing accuracy $\left(\mathrm{H}_{5}\right)$. Our findings indicate a significant overestimation of customer price importance by the salesperson with increasing product knowledge of the customer $\left(\mathrm{H}_{5}: \mathrm{b}=.11, \mathrm{SE}=.06, \mathrm{p}<.05\right)$. This overestimation occurs because salespeople do not seem to recognize that customers with higher product knowledge have lower CPI in fact. The controls have no significant effects on CPI sensing accuracy.

---- Insert Table 3 about here ----

\section{Discussion}

Although retailing literature stresses the importance of salespeople's effectiveness (Haas and Kenning 2014) and emphasizes the relevance of interpersonal perceptions in salespersoncustomer interactions (Van Dolen et al. 2002), how salespeople form customer perceptions in retail price negotiations and to what effect remains unexplored. Therefore, CPI sensing — which we newly introduce and define as forming perceptions of the relevance a customer attaches to 
price compared to other (benefit-related) product attributes — should be an essential precondition for a salesperson's negotiation performance.

The central goal of our study was to verify whether CPI sensing accuracy constitutes a success factor in retailing and to show that acquiring CPI information provides the salesperson with a veritable strategic advantage in price negotiations. Thereby, we address the omission in existing research regarding the process of gathering and using price-related information during sales interactions. We provide evidence that CPI sensing accuracy increases the salesperson's negotiation performance, especially when the salesperson perceives high revenue goal importance. However, the salesperson needs at least a moderate degree of customer orientation to prevent detrimental effects of CPI sensing accuracy on the customer's purchase intention. Regarding CPI sensing antecedents, we demonstrate that customer age and relationship length lead to an underestimation and customer product knowledge to an overestimation of CPI by the salesperson.

\section{Theoretical Implications}

Our research makes important contributions to retailing, sales and negotiation literature. Retailing researchers have spent considerable effort on examining methods to customize prices in order to increase profit margins (Grewal et al. 2011; Johnson, Tellis, and Ip 2013). By introducing CPI sensing in discount negotiations as an important tool to optimize discounts for individual customers, we shed light on an effective technique which has not received much attention in prior retailing literature. Thereby, we support and expand findings from prior retailing literature that salespeople who understand their customers well not only perform superiorly in terms of building customer relationships (Beatty et al. 1996; Reynolds and Beatty 1999) but also immediately with respect to monetary outcomes.

Moreover, our study contributes to the literature on the delegation of pricing authority to the sales force (Frenzen et al. 2010; Stephenson, Cron, and Frazier 1979). This stream of 
research has found contradictory results regarding the effectiveness of this decision to delegate (Homburg, Jensen, and Hahn 2012). From a theoretical perspective, the delegation of pricing authority to salespeople should lead to higher profits, because salespeople are closer to the market than their management and therefore should possess superior knowledge about their customers’ price-related needs (Frenzen et al. 2010). However, these theoretical predictions have not always been confirmed in practice (Stephenson, Cron, and Frazier 1979). We are able to show that the assumption that salespeople possess superior knowledge about their customers’ price importance may not always and automatically hold true.

Instead, a reasonable assumption is that salespeople exhibit considerable heterogeneity regarding their customer-related price knowledge. Our findings indicate that cognitive biases may reduce the informational edge salespeople have compared to their management and lead to suboptimal salesperson behavior in negotiations. Consequently, we propose that the effect of delegating pricing authority to salespeople on achieved profit should be strongly affected by the CPI sensing proficiency of the salesforce. Thus, integrating CPI sensing accuracy into models that try to forecast the impact of pricing authority delegation on performance could enhance the models' explanatory power.

Related to this aspect, a promising avenue for future research should be to further investigate CPI sensing cues, like for example customer behavior. In our study, we identify three heuristic cues which distort salespeople’s perceptions of CPI. Thereby, our study focuses on heuristic processing of salespeople. However, a recent study by Hall, Ahearne, and Sujan (2015) demonstrates that salespeople use both intuitive and deliberate judgment processes. Thus, investigating the combination of heuristic and analytic processing may help to further elucidate the process of CPI sensing.

Moreover, future research might engage in a deeper examination of differences between CPI sensing and sensing of other price-related constructs such as customers’ price sensitivity. The most important difference between CPI and price-sensitivity is the relative nature of CPI 
(i.e., CPI sets the importance of price in relation to the importance of other product attributes). This difference is important for our conceptual model, since we suppose that "price sensitivity sensing” would not yield equal effects on retail performance. Only relying on price sensitivity to assess customers' negotiation behavior might induce the salesperson to choose the wrong argumentation strategy. For instance, a customer may state to be very price-sensitive, but at the same time attach an even higher importance to other product attributes. In this case the salesperson would not focus on the benefits the customer values most.

Even though we invested great effort into the development of a rigorous study there are limitations to our research design. Specifically, while we suggest heuristic cues to distort salespeople’s CPI sensing accuracy we do not measure all of these cues from salespeople’s viewpoint. Customer age and product knowledge are rated by the customer. Thus, their effects on CPI sensing accuracy might be even higher if salespeople's perceptions were taken into account.

Furthermore, we test the effect of CPI sensing accuracy on negotiated discount with help of an absolute difference measure. While an additional analysis provides empirical evidence that in our study the direction of misperception does not matter regarding negotiation outcomes, there may be contingencies which render the direction of the CPI misperception more important. For instance, in a business-to-business negotiation context owing to the enhanced negotiation experience of purchasing agents, underestimating CPI may entail more dire consequences for the salesperson's price enforcement than overestimating the purchasing agent's CPI which may entail a more cautious bargaining stance.

\section{Managerial Implications}

Our findings also have important, actionable implications for retailing practice. The study clearly shows that retail salespeople should engage in CPI sensing to increase negotiation success. By acquiring individual CPI information, salespeople obtain a strategic advantage in 
discount negotiations because they are able to adjust their argumentation strategy to the individual customer. In our study, accurate CPI sensing helps salespeople to grant a discount that is on average $1.96 \%$ lesser (6.57\% compared to $8.53 \%)$ while maintaining the customers' purchase intention. This reduction saves the salesperson an average of \$616 per car sold which is a significant increase of the retail margin.

This positive impact on profit is even enhanced if the salesperson considers the revenue goal to be of high importance. Thus, retail managers should stress the importance of revenue goals and provide salespeople with incentives to attain them. Moreover, if salespeople engage in CPI sensing and combine it with a strong customer orientation, they are able to alleviate negative effects of CPI sensing accuracy on purchase intention. Thus, in line with prior literature retail managers should train their salespeople to be customer oriented and to adapt to individual customers. In this respect, our findings suggest that CPI sensing might also represent a valuable skill in retail interactions without discount negotiations. Salespeople who make accurate CPI assessments may be better able to address their customers’ needs, offer them products that correspond to their price importance, and thus, sell more and higher priced products.

However, the sales force should be well trained in CPI sensing in order to avoid misclassifying customers. We provide starting points for such trainings by identifying cues that lead to misperceptions of CPI. By relying on customer age as CPI sensing cue salespeople underestimate CPI on average by $14 \%$. The average underestimation when relying on customer-salesperson relationship length amounts to $1.2 \%$, but increases dramatically for longer relationships (ten years relationship length would induce an underestimation of 9.3\%). Furthermore, salespeople appear to neglect information on customer product knowledge for CPI sensing. This neglect leads salespeople to a CPI overestimation by $9.5 \%$ for customers with average product knowledge. Since our findings indicate that relying on heuristic cues 
leads to significant misperceptions, salespeople should try to engage more in analytic processing in order to form more accurate CPI perceptions.

In essence, we strongly encourage practitioners in the retail context to foster their sales force's CPI sensing proficiency. If salespeople are able to improve their CPI sensing accuracy and adapt their negotiation strategy accordingly, they achieve higher levels of negotiation success without sacrificing customers' purchase intention, fostering salespeople's financial performance. 


\section{References}

Ayres, Ian, and Peter Siegelman (1995), "Race and gender discrimination in bargaining for a new car,” The American Economic Review, 304-321.

Bagozzi, Richard P. and Youjae Yi (1988), "On the Evaluation of Structural Equation Models,” Journal of the Academy of Marketing Science, 16 (1), 74-94.

Beatty, Sharon E., Morris Mayer, James E. Coleman, Kristy E. Reynolds and Jungki Lee (1996), “Customer-sales associate retail relationships,” Journal of Retailing, 72 (3), 223247.

Bell, Simon J., Seigyoung Auh and Karen Smalley (2005), “Customer relationship dynamics: service quality and customer loyalty in the context of varying levels of customer expertise and switching costs," Journal of the Academy of Marketing Science, 33 (2), 169-183.

Borkenau, Peter and Anette Liebler (1992), "Trait inferences: Sources of validity at zero acquaintance,” Journal of Personality and Social Psychology, 62 (4), 645-657.

Brett, Joan F., Robin L. Pinkley and Ellen F. Jackofsky (1996), “Alternatives to having a BATNA in dyadic negotiation: The influence of goals, self-efficacy, and alternatives on negotiated outcomes," The International Journal of Conflict Management, 7 (2), 121-138.

Brewer, Marilyn B. (1988), “A dual process model of impression formation,” Advances in social cognition, 1, 1-36.

Brunswik, Egon (1955), "Representative design and probabilistic theory in a functional psychology,” Psychological Review, 62 (3), 193-217.

Campbell, W. Keith and Constantine Sedikides (1999), "Self-threat magnifies the self-serving bias: A meta-analytic integration,” Review of General Psychology, 3 (1), 23-43.

Campion, Michael A. and Robert G. Lord (1982), "A control systems conceptualization of the goal-setting and changing process," Organizational Behavior and Human Performance, 30 (2), 265-287.

Chaiken, Shelly and Yaacov Trope (1999), Dual-process theories in social psychology, New York: Guilford Press.

Clopton, Stephen W. (1984), "Seller and buying firm factors affecting industrial buyers' negotiation behavior and outcomes,” Journal of Marketing Research, 21 (1), 39-53.

Cohen, Jacob, P., Stephen G. West and Leona S. Aiken (2003), Applied Multiple Regression/ Correlation Analysis for the Behavioral Sciences, Mahwah, New Jersey: Erlbaum.

Colbert, Amy E., Amy L. Kristof-Brown, Bret H. Bradley and Murray R. Barrick (2008), "CEO Transformational Leadership: The role of goal importance congruence in top," Academy of Management Journal, 51 (1), 81-96.

CSO Insights. (2011). Sales Performance Optimization Benchmark Report. 1-97.

Cuddy, Amy J. C. and Susan T. Fiske (2002), "Doddering but dear: Process, content, and function in stereotyping of older persons," in Ageism: Stereotyping and prejudice against older persons, Todd D. Nelson, ed. Cambridge, MA: MIT Press, 3-26. 
Dalrymple, Douglas J., P. Ronald Stephenson and William L. Cron (1981), “Gross margin sales compensation plans,” Industrial Marketing Management, 10 (3), 219-224.

De Dreu, Carsten K.W. (2003), “Time pressure and closing of the mind in negotiation,” Organizational Behavior and Human Decision Processes, 91 (2), 280-295.

De Dreu, Carsten K.W. and Gerben A. Van Kleef (2004), “The influence of power on the information search, impression formation, and demands in negotiation,” Journal of Experimental Social Psychology, 40 (3), 303-319.

Dolan, Robert. J. and Hermann Simon (1996), Power pricing. New York: The Free Press.

Edwards, Jeffrey R. (1994), "Regression analysis as an alternative to difference scores," Journal of Management, 20 (3), 683-689.

_ (1995), "Alternatives to difference scores as dependent variables in the study of congruence in organizational research," Organizational Behavior and Human Decision Processes, 64 (3), 307-324.

Eisenhardt, Kathleen M. (1989), “Agency theory: An assessment and review,” Academy of Management Review, 14 (1), 57-74.

Evans, Kenneth R. and Richard F. Beltramini (1987), “A theoretical model of consumer negotiated pricing: An orientation perspective,” Journal of Marketing, 51 (2), 58-73.

Evans, Jonathan St. B. T. (2008), "Dual-processing accounts of reasoning, judgment, and social cognition,” Annu. Rev. Psychol., 59, 255-278.

Fisher, Roger and William L. Ury (1981), Getting to yes. Negotiating an agreement without giving in, Boston: Houghton Mifflin.

Fornell, Claes and David F. Larcker (1981), "Evaluating structural equation models with unobserved variables and measurement error,” Journal of Marketing Research, 18 (1), 3950 .

French Jr, John R.P. and Bertram Raven (1959), “The bases of social power,” in Group dynamics, D. Cartwright and A. Zander, ed. New York: Harper \& Row.

Frenzen, Heiko, Ann-Kristin Hansen, Manfred Krafft, Murali K. Mantrala and Simone Schmidt (2010), "Delegation of pricing authority to the sales force: An agency-theoretic perspective of its determinants and impact on performance,” International Journal of Research in Marketing, 27 (1), 58-68.

Fu, Frank Q., Keith A. Richards and Eli Jones (2009), “The motivation hub: Effects of goal setting and self-efficacy on effort and new product sales," Journal of Personal Selling and Sales Management, 29 (3), 277-292.

Gauri, Dinesh K., Minakshi Trivedi, and Dhruv Grewal (2008), "Understanding the determinants of retail strategy: An empirical analysis,” Journal of Retailing, 84 (3), 256267.

Gill, Michael J. and William B. Jr. Swann (2004), “On What It Means to Know Someone: A Matter of Pragmatics,” Journal of Personality and Social Psychology, 86 (3), 405-418. 
Goff, Brent G., James S. Boles, Danny N. Bellenger and Carrie Stojack (1997), “The influence of salesperson selling behaviors on customer satisfaction with products," Journal of Retailing, 73 (2), 171-183.

Grewal, Dhruv, Kusum L. Ailawadi, Dinesh Gauri, Kevin Hall, Praveen Kopalle and Jane R. Robertson (2011), “Innovations in retail pricing and promotions,” Journal of Retailing, 87, 43-52.

Haas, Alexander and Peter Kenning (2014), “Utilitarian and hedonic motivators of shoppers' decision to consult with salespeople,” Journal of Retailing, 90 (3), 428-441.

Haefner, James E. (1977), “Race, age, sex, and competence as factors in employer selection of the disadvantaged.," Journal of Applied Psychology, 62 (2), 199-202.

Hall, Ahearne, Sujan

Hamilton, Rebecca W. and Joydeep Srivastava (2008), "When $2+2$ is not the same as $1+3$ : Variations in price sensitivity across components of partitioned prices," Journal of Marketing Research, 45 (4), 450-461.

Hofmann, David A. (1997). "An overview of the logic and rationale of hierarchical linear models.” Journal of Management, 23 (6), 723-744.

Holbrook, Morris B. and Robert M. Schindler (1996), "Market segmentation based on age and attitude toward the past: Concepts, methods, and findings concerning nostalgic influences on customer tastes,” Journal of Business Research, 37 (1), 27-39.

Hollenbeck, John R. and Charles R. Williams (1987), "Goal importance, self-focus, and the goal-setting process,” Journal of Applied Psychology, 72 (2), 204-211.

Homburg, Christian, Ove Jensen and Alexander Hahn (2012), "How to organize pricing? Vertical delegation and horizontal dispersion of pricing authority,” Journal of Marketing, 76 (5), 49-69.

_ - Jan Wieseke and Torsten Bornemann (2009), "Implementing the marketing concept at the employee-customer interface: The role of customer need knowledge,” Journal of Marketing, 73 (4), 64-81.

—_— \& Wayne D. Hoyer (2009), “Social identity and the service-profit chain,” Journal of Marketing, 73 (2), 38-54.

Hox, Joop J. (2010), Multilevel Analysis: Techniques and Applications (Quantitative Methodology), New York and Hove: Taylor \& Francis.

Huber, Vandra L. and Margaret A. Neale (1987), "Effects of self-and competitor goals on performance in an interdependent bargaining task," Journal of Applied Psychology, 72 (2), 197-203.

Hüffmeier, Joachim, Philipp A. Freund, Alfred Zerres, Klaus Backhaus and Guido Hertel (2014), "Being tough or being nice? A meta-analysis on the impact of hard- and softline strategies in distributive negotiations,” Journal of Management, 40 (3), 866-892.

IBISWorld Industry Information. (2014), "Market Research Reports,” http://www.ibisworld.com, (accessed 26 March, 2014). 
Jap, Sandy, Diana C. Robertson and Ryan Hamilton (2011), “The dark side of rapport: Agent misbehavior face-to-face and online,” Management Science, 57 (9), 1610-1622.

Jaworski, Bernard J. and Deborah J. MacInnis (1989), “Marketing jobs and management controls: Toward a framework,” Journal of Marketing Research, 26, 406-419.

John, George and Barton Weitz (1989), "Salesforce compensation: an empirical investigation of factors related to use of salary versus incentive compensation," Journal of Marketing Research, 26 (1), 1-14.

Johnson, Joseph, Gerard J. Tellis and Edward H. Ip (2013), "To whom, when, and how much to discount? A constrained optimization of customized temporal discounts," Journal of Retailing, 89 (4), 361-373.

Joseph, Kissan (2001), “On the optimality of delegating pricing authority to the sales force,” Journal of Marketing, 65 (1), 62-70.

Kelley, Harold H. (2013), Personal relationships: Their structures and processes, Psychology Press.

Kopalle, Praveen, Dipayan Biswas, Pradeep K. Chintagunta, Jia Fan, Koen Pauwels, Brian T. Ratchford and James A. Sills (2009), "Retailer pricing and competitive effects," Journal of Retailing, 85 (1), 56-70.

Lax, David A. and James K. Sebenius (1986), “Interests: The measure of negotiation,” Negotiation Journal, 2 (1), 73-92.

Levy, Michael and Arun Sharma (1994), "Adaptive selling: the role of gender, age, sales experience, and education,” Journal of Business Research, 31 (1), 39-47.

Levy, Michael, Dhruv Grewal, Praveen Kopalle and James Hess (2004), "Emerging trends in retail pricing practice: implications for research,” Journal of Retailing, 80 (3), xiii-xxi.

Lichtenstein, Donald R., Peter H. Bloch and William C. Black (1988), "Correlates of price acceptability,” Journal of Consumer Research, 15 (2), 243-252.

Marks, T. (2013), “Learning how to bargain can reap big bucks,” Consumer Reports Magazine, http://www.consumerreports.org/cro/magazine/2013/08/how-to-bargain/index.htm, (accessed April 7, 2014).

McCloy, Rodney A., Eric D. Heggestad and Charlie L. Reeve (2005), "A silk purse from the sow's ear: Retrieving normative information from multidimensional forced-choice items," Organizational Research Methods, 8 (2), 222-248.

Mishra, Birendra K. and Ashutosh Prasad (2005), "Delegating pricing decisions in competitive markets with symmetric and asymmetric information,” Marketing Science, 24 (3), 490-497.

Montepare, Joann M. and Leslie Zebrowitz-McArthur (1988), "Impressions of people created by age-related qualities of their gaits,” Journal of Personality and Social Psychology, 55 (4), 547-556.

Muthén, Linda K. and Bengt O. Muthén (2012), Mplus User’s Guide, Los Angeles, CA: Muthén \& Muthén. 
Murnighan, J. Keith, Linda Babcock, Leigh Thompson, and Madan Pillutla (1999), “The information dilemma in negotiations: Effects of experience, incentives and integrative potential,” The International Journal of Conflict Management, 10 (4), 313-339.

Nagle, Thomas T. and Reed K. Holden (1995), The strategy and tactics of pricing, Englewood Cliffs, New Jersey: Prentice Hall.

Park, Chan-Wook and Byeong-Joon Moon (2003), "The relationship between product involvement and product knowledge: Moderating roles of product type and product knowledge type,” Psychology \& Marketing, 20 (11), 977-997.

Puccinelli, Nancy M., Ronald C. Goodstein, Dhruv Grewal, Robert Price, Priya Raghubir and David Stewart (2009), "Customer experience management in retailing: Understanding the buying process,” Journal of Retailing, 85 (1), 15-30.

Rao, Akshay R. and Wanda A. Sieben (1992), “The effect of prior knowledge on price acceptability and the type of information examined," Journal of Consumer Research, 19 (2), 256-270.

Reynolds, Kristy E. and Sharon E. Beatty (1999), "Customer benefits and company consequences of customer-salesperson relationships in retailing,” Journal of Retailing, 75 (1), 11-32.

Rozin, Paul and Edward B. Royzman (2001), "Negativity bias, negativity dominance, and contagion,” Personality and Social Psychology Review, 5 (4), 296-320.

Saxe, Robert and Barton A. Weitz (1982), "The SOCO Scale: A Measure of the Customer Orientation of Salespeople,” Journal of Marketing Research, 19 (3), 343-351.

Spiro, Rosann L. and Barton A. Weitz (1990), “Adaptive selling: Conceptualization, measurement, and nomological validity,” Journal of Marketing Research, 27 (1), 61-69.

Stephenson, P. Ronald, William L. Cron and Gary L. Frazier (1979), “Delegating Pricing Authority to the Sales Force: The Effects on Sales and Profit Performance,” Journal of Marketing, 43 (2), 21-28.

Stuhlmacher, Alice F. and Matthew V. Champagne (2000), "The impact of time pressure and information on negotiation process and decisions," Group Decision and Negotiation, 9 (6), 471-491.

Swann, William B. (1984), “Quest for accuracy in person perception: a matter of pragmatics,” Psychological Review, 91 (4), 457-477.

Szymanski, David M. (1988), "Determinants of Selling Effectiveness: The Importance of Declarative Knowledge to the Personal Selling Concept,” Journal of Marketing, 52 (1), 6477.

and Gilbert A. Jr. Churchill (1990), “Client evaluation cues: a comparison of successful and unsuccessful salespeople,” Journal of Marketing Research, 27 (2), 163-174.

Thomas, Raymond W., Geoffrey N. Soutar and Maria M. Ryan (2001),"The selling orientation-customer orientation (SOCO) scale: A proposed short form," Journal of Personal Selling \& Sales Management, 21 (1), 63-69. 
Thompson, Leigh (1990), "Negotiation behavior and outcomes: Empirical evidence and theoretical issues,” Psychological Bulletin, 108 (3), 515-532.

_ and Reid Hastie (1990), "Social Perception in Negotiation,” Organizational Behavior and Human Decision Processes, 47 (1), 98-123.

Van Dolen, Willemijn, Jos Lemmink, Ko De Ruyter and Ad De Jong (2002), “Customer-sales employee encounters: a dyadic perspective,” Journal of Retailing, 78 (4), 265-279.

Vosgerau, Joachim, Erin Anderson and William T. Ross Jr. (2008), “Can inaccurate perceptions in business-to-business (B2B) relationships be beneficial?,” Marketing Science, 27 (2), 205-224.

Wagner, Judy A., Noreen M. Klein and Janet E. Keith (2001), "Selling strategies: The effects of suggesting a decision structure to novice and expert buyers," Journal of the Academy of Marketing Science, 29 (3), 289-306.

Wakefield, Kirk L. and J. Jeffrey Inman (2003), "Situational price sensitivity: the role of consumption occasion, social context and income,” Journal of Retailing, 79 (4), 199-212.

Weitz, Barton A., Harish Sujan, and Mita Sujan (1986), "Knowledge, motivation, and adaptive behavior: A framework for improving selling effectiveness,” Journal of Marketing, 174191.

Wieseke, Jan, Sascha Alavi and Johannes Habel (2014), "Willing to Pay More, Eager to Pay Less: The Role of Customer Loyalty in Price Negotiations,” Journal of Marketing, 78 (6), 17-37.

__ Florian Kraus, Michael Ahearne and Sven Mikolon (2012), "Multiple Identification Foci and Their Countervailing Effects on Salespeople's Negative Headquarters Stereotypes,” Journal of Marketing, 76 (3), 1-20.

Xia, Lan, Monika Kukar-Kinney and Kent B. Monroe (2010), "Effects of consumers’ efforts on price and promotion fairness perceptions," Journal of Retailing, 86 (1), 1-10.

Zebrowitz, Leslie A. and Mary Ann Collins (1997), “Accurate social perception at zero acquaintance: The affordances of a Gibsonian approach,” Personality and Social Psychology Review, 1 (3), 204-223.

Zeithaml, Valarie A. (1984), "Issues in conceptualizing and measuring consumer response to price,” in Advances in Consumer Research, Vol. 11, Thomas C. Kinnear, ed. Provo, UT: Association for Consumer Research, 612-616.

Zetik, Deborah C. and Alice F. Stuhlmacher (2002), "Goal Setting and Negotiation Performance: A Meta-Analysis,” Group Processes and Intergroup Relations, 5 (1), 35-52. 
TABLE 1

Correlations, Means, and Standard Deviations

\begin{tabular}{|c|c|c|c|c|c|c|c|c|c|c|c|c|c|c|}
\hline Variable & 1 & 2 & 3 & 4 & 5 & 6 & 7 & 8 & 9 & 10 & 11 & 12 & 13 & 14 \\
\hline \multicolumn{15}{|l|}{ CPI sensing variables } \\
\hline \multicolumn{15}{|l|}{ 1. $\mathrm{CPI}^{1}$} \\
\hline 2. Salesperson's CPI perception & $.209 * *$ & & & & & & & & & & & & & \\
\hline 3. CPI sensing accuracy & $.401 * *$ & $.484 * *$ & & & & & & & & & & & & \\
\hline \multicolumn{15}{|l|}{ CPI sensing accuracy outcome } \\
\hline 4. Negotiated discount (in percent) & $-.100 *$ & $-.112 *$ & $-.203^{* *}$ & & & & & & & & & & & \\
\hline 5. Purchase intention & $-.103^{*}$ & $-.136 * *$ & $-.115^{*}$ & $.179 * *$ & & & & & & & & & & \\
\hline \multicolumn{15}{|l|}{ Moderators } \\
\hline 6. Revenue goal importance & -.048 & -.012 & .064 & -.010 & .002 & & & & & & & & & \\
\hline 7. Salesperson's customer orientation & -.066 & $-.105^{*}$ & -.073 & $.168 * *$ & $.219 * *$ & $.105 *$ & & & & & & & & \\
\hline \multicolumn{15}{|l|}{ CPI sensing cues } \\
\hline 8. Customer age & $-.109 *$ & $-.204 * *$ & $-.176^{* *}$ & $.194^{* *}$ & $.146^{* *}$ & $.110^{*}$ & $.138 * *$ & & & & & & & \\
\hline 9. Customer product knowledge & -.094 & -.004 & -.079 & $.142 *$ & .081 & -.010 & -.004 & & & & & & & \\
\hline 10. Relationship length (in years) & $-.116 *$ & $-.165^{* *}$ & $-.108 *$ & $.172 * *$ & $.240 * *$ & .065 & $.174^{* *}$ & $.188^{* *}$ & & & & & & \\
\hline \multicolumn{15}{|l|}{ Controls } \\
\hline 11. Encounter Length & -.051 & $-.128 * *$ & -.074 & $.202 * *$ & $.268 * *$ & .047 & $.154^{* *}$ & .079 & .089 & $.166^{* *}$ & & & & \\
\hline 12. Product Price Level (in €) & $-.243^{* *}$ & $-.247 * *$ & $-.171^{* *}$ & $.155^{* *}$ & .025 & .033 & $.132 * *$ & $.222 * *$ & $.292 * *$ & $.148 * *$ & .070 & & & \\
\hline 13. Salesperson's Experience (in years) & $-.106 *$ & $-.179 * *$ & -.088 & $.238 * *$ & .051 & .022 & .009 & $.102 *$ & $.105^{*}$ & $.193 * *$ & .079 & $.134 * *$ & & \\
\hline 14. Direction of Misperception & $-.490 * *$ & $.766 * *$ & $.158 * *$ & .023 & .017 & -.024 & .057 & .107 & -.080 & .029 & .096 & .064 & .096 & \\
\hline Mean & 4.86 & 4.81 & 1.25 & 7.49 & 5.66 & 4.15 & 4.92 & 44.75 & 4.15 & 1.31 & 42.54 & 29416 & 12.89 & -2 \\
\hline Standard deviation & 1.21 & 1.52 & 1.20 & 6.47 & 1.59 & 1.26 & 1.59 & 14.68 & 1.59 & 3.73 & 33.37 & 17423 & 9.81 & -2 \\
\hline
\end{tabular}

${ }^{1} \mathrm{CPI}=$ Customer price importance ${ }^{2}$ Categorial variable

${ }^{*} \mathrm{p}<.05 ;{ }^{* *} \mathrm{p}<.01$ (two-tailed) 
TABLE 2

Results for CPI Sensing Accuracy Consequences

\begin{tabular}{|c|c|c|c|c|c|c|c|c|c|}
\hline \multirow[b]{2}{*}{ Independent variable } & \multirow[b]{2}{*}{ Hypothesis } & \multicolumn{4}{|c|}{ Model 1 (without interactions) } & \multicolumn{4}{|c|}{ Model 2 (with interactions) } \\
\hline & & $\begin{array}{c}\text { Effect on } \\
\text { negotiated } \\
\text { discount }\end{array}$ & SE & $\begin{array}{l}\text { Effect on } \\
\text { purchase } \\
\text { intention }\end{array}$ & SE & $\begin{array}{c}\text { Effect on } \\
\text { negotiated } \\
\text { discount }\end{array}$ & SE & $\begin{array}{l}\text { Effect on } \\
\text { purchase } \\
\text { intention }\end{array}$ & SE \\
\hline \multicolumn{10}{|l|}{ Main effects } \\
\hline CPI sensing accuracy & $\mathrm{H}_{1}(-)$ & $-.96 *$ & .48 & -.10 & .08 & $-1.02 *$ & .47 & -.11 & .08 \\
\hline Customer orientation & & .60 & .57 & $.32^{* *}$ & .10 & .59 & .53 & $.31^{* *}$ & .09 \\
\hline Revenue goal importance & & -.47 & .49 & .01 & .09 & -.40 & .48 & .04 & .09 \\
\hline \multicolumn{10}{|l|}{ Interaction effects } \\
\hline CPI sensing X Revenue goal importance & $\mathrm{H}_{2}(-)$ & - & - & - & - & $-.73^{*}$ & .41 & -.11 & .07 \\
\hline CPI sensing X Customer orientation & $\mathrm{H}_{3}(+)$ & - & - & - & - & -.14 & .26 & $.11^{* *}$ & .04 \\
\hline \multicolumn{10}{|l|}{ Controls } \\
\hline Encounter Length & & $1.32 * *$ & .40 & $.37 * *$ & .08 & $1.34 * *$ & .40 & $.34 * *$ & .08 \\
\hline Product Price Level & & .57 & .46 & .02 & .08 & .50 & .49 & .02 & .08 \\
\hline Direction of Misperception ${ }^{1}$ & & .51 & .42 & .06 & .08 & .56 & .42 & .04 & .08 \\
\hline Negotiated discount & & - & - & .00 & .02 & - & - & .01 & .03 \\
\hline
\end{tabular}

${ }^{*} \mathrm{p}<.05 ;{ }^{* *} \mathrm{p}<.01$ (one-tailed); SE = Standard Error; ${ }^{1}$ Direction of Misperception: 1 = Overestimation, -1 = Underestimation

As we conducted a multi-level path analysis unstandardized path coefficients are reported. 
TABLE 3

Results for CPI Sensing Accuracy Antecedents

\begin{tabular}{|c|c|c|c|c|c|}
\hline Hypothesis & Independent variable & $\begin{array}{c}\text { Effect on CPI } \\
\text { sensing accuracy } \\
\text { (raw difference) }\end{array}$ & SE & Over- or underestimation & Hypothesis confirmed? \\
\hline $\mathrm{H}_{4}$ & Customer age & $-.019 * *$ & .008 & Underestimation $^{1}$ & $\checkmark$ \\
\hline $\mathrm{H}_{5}$ & $\begin{array}{c}\text { Customer product } \\
\text { knowledge }\end{array}$ & $.109 *$ & .064 & Overestimation & $\checkmark$ \\
\hline $\mathrm{H}_{6}$ & $\begin{array}{l}\text { Customer-SP relationship } \\
\text { length }\end{array}$ & $-.058 *$ & .031 & Underestimation & $\checkmark$ \\
\hline
\end{tabular}


FIGURE 1

The Role of CPI Sensing in Retail Price Negotiations - Illustration of the Research Void

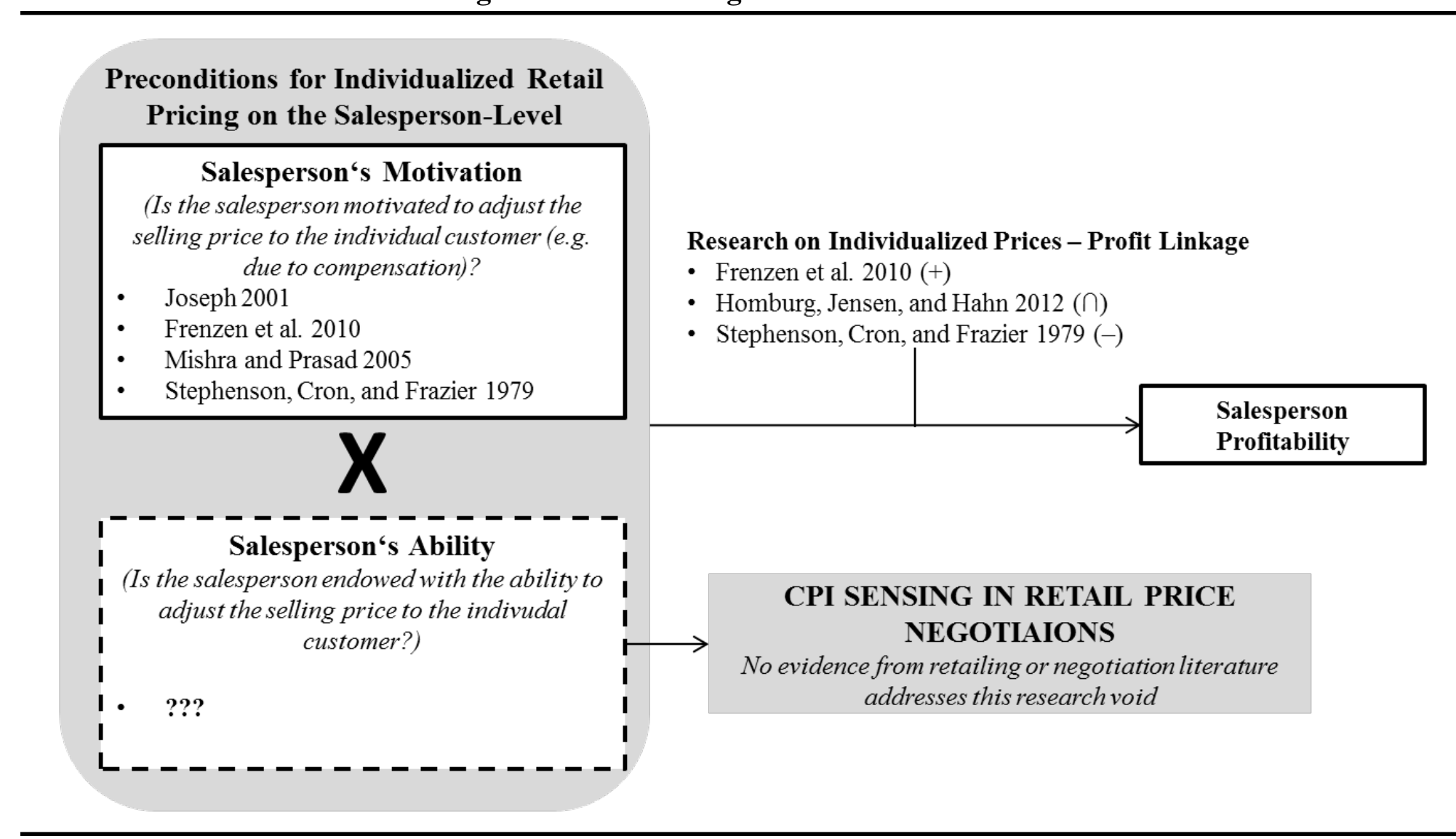


FIGURE 2

Conceptual Framework: A Comprehensive Account of CPI Sensing in Retail Price Negotiations

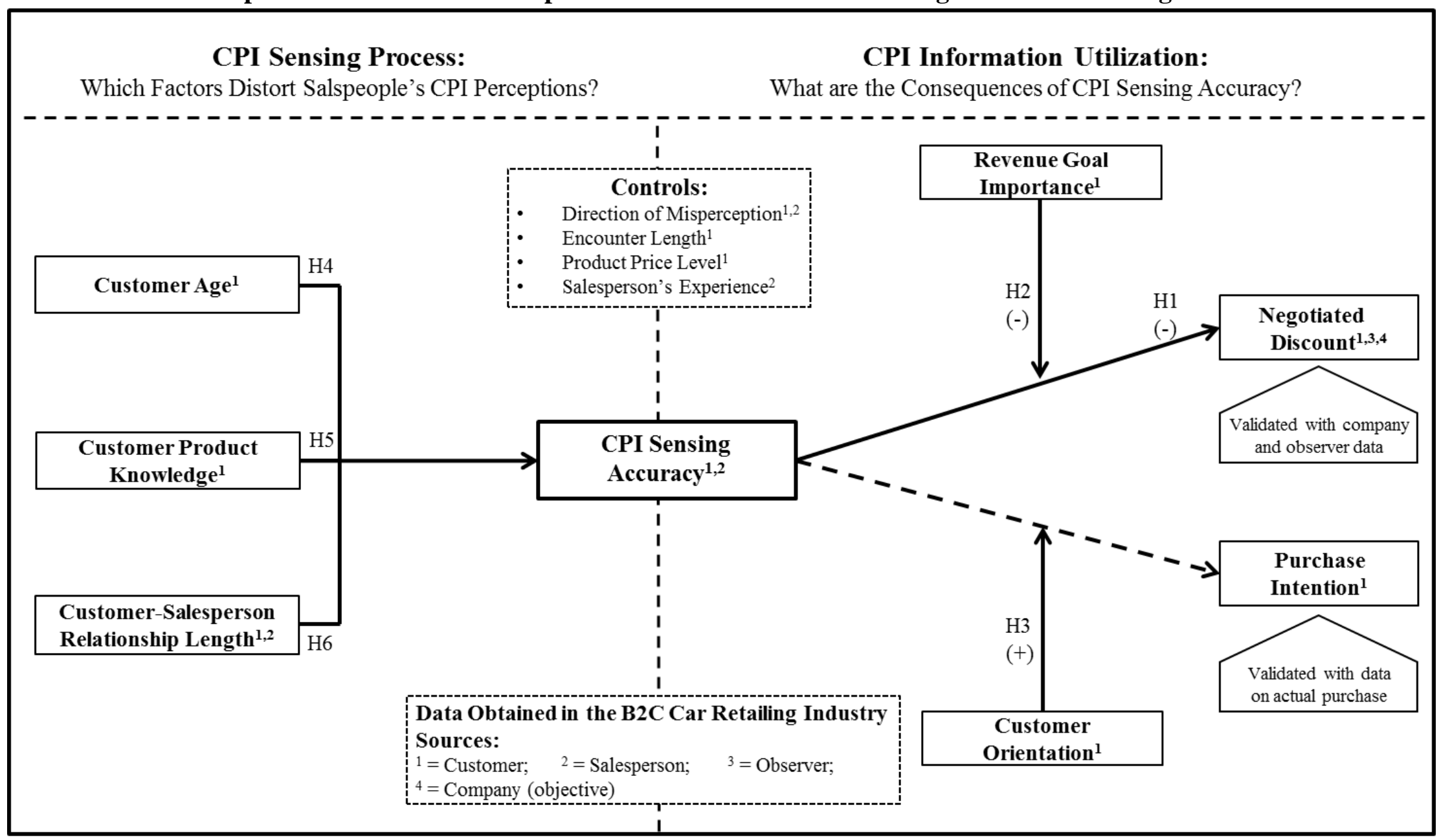

$\mathrm{CPI}=$ Customer Price Importance

The dashed arrow indicates that we do not hypothesize a direct effect of CPI sensing on purchase intention 
FIGURE 3

How Does CPI Sensing Accuracy Influence the Negotiated Discount? An Illustration of CPI Sensing Accuracy Consequences

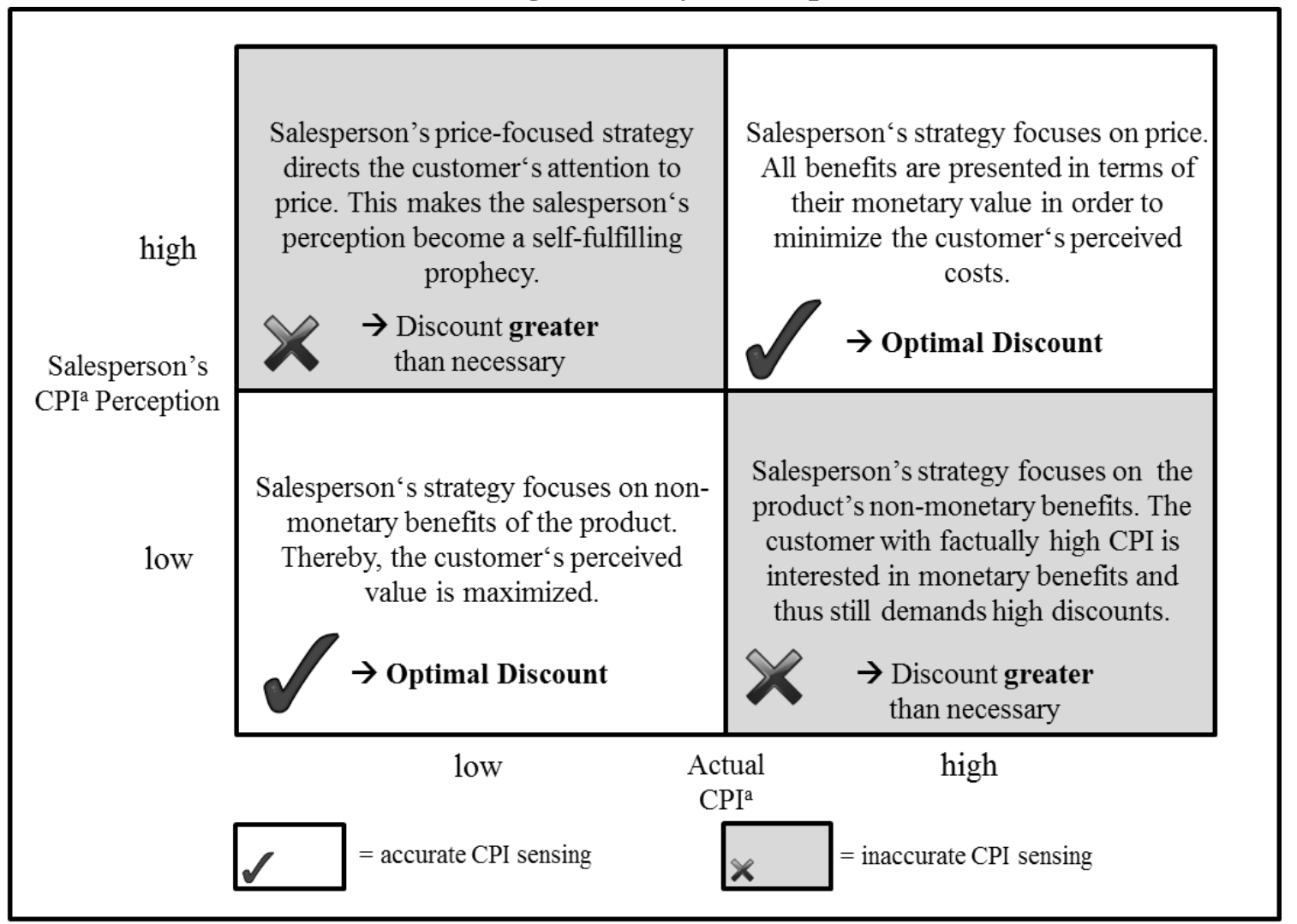

${ }^{\mathrm{a} C u s t o m e r ~ p r i c e ~ i m p o r t a n c e ~}$ 
FIGURE 4

The Moderating Role of Revenue Goal Importance on the Link between CPI Sensing Accuracy and Negotiated Discount

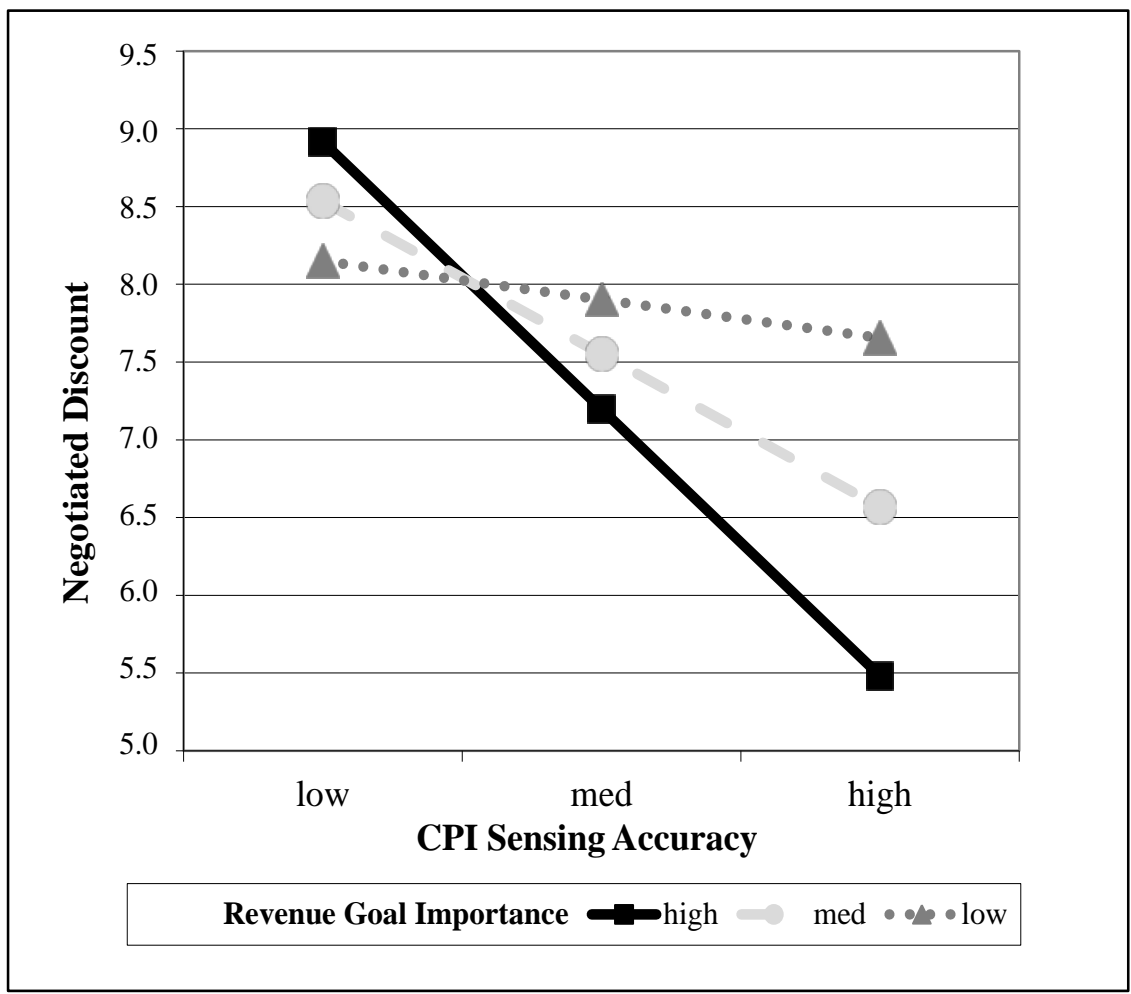

The Moderating Role of Customer Orientation on the Link between CPI Sensing Accuracy and Purchase Intention

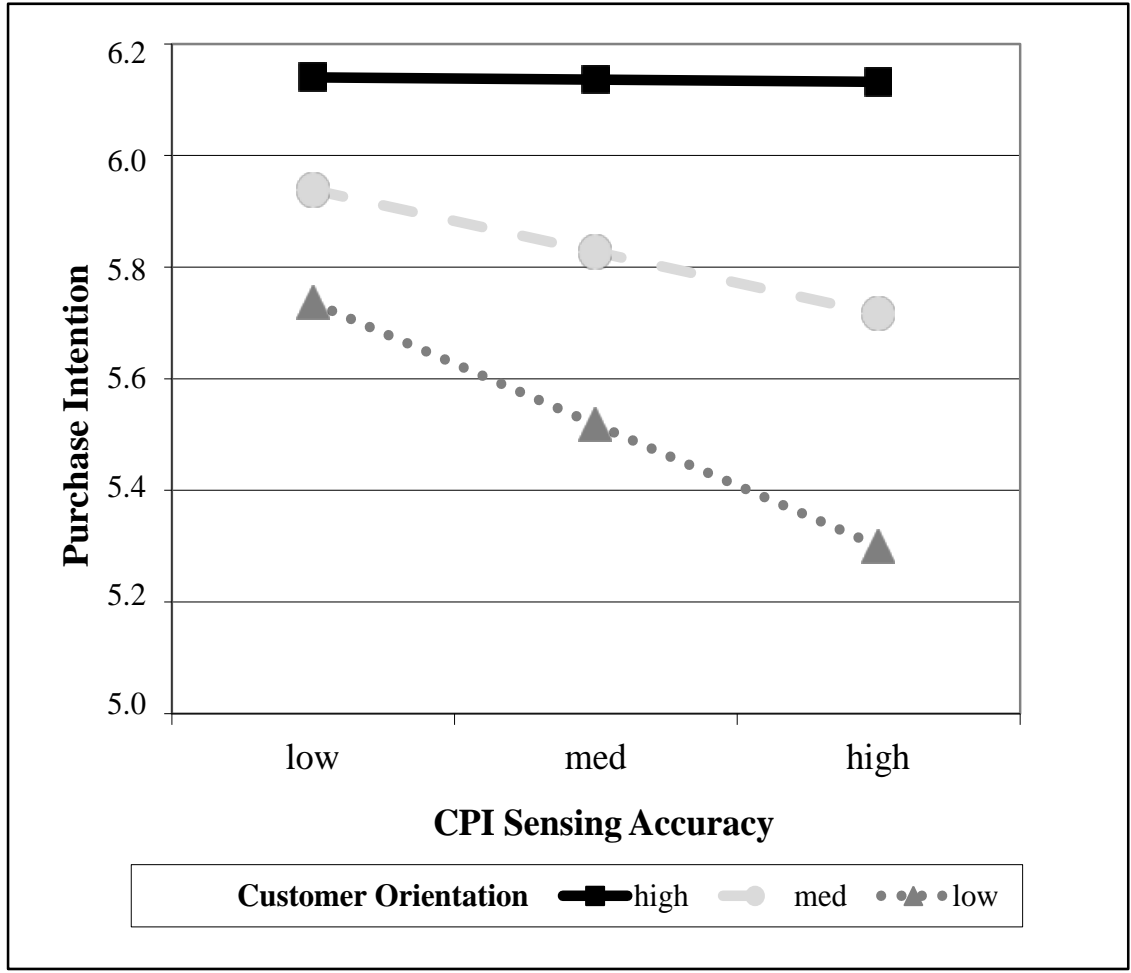




\section{APPENDIX}

Constructs and Items

CR AVE $\alpha$

CPI Sensing (Homburg, Wieseke \& Bornemann 2009) ${ }^{1,2}$

We are interested in how important price is for you compared to other factors with respect to buying a car. Please consider the following factors and rate what ranking position price has for you among those with respect to the importance for your purchase decision. Thus, if price is the most important factor, rate "1", if it is the second most important "2" and so forth.

Please rank the relative importance of price compared to...

...convenience; service; security; shopping enjoyment; additional features

Please note that we recoded the scale by subtracting the price ranking rated by salesperson and customer from 7 to ensure that higher values reflected higher CPI

\begin{tabular}{l}
\hline Negotiation Outcomes \\
\hline Negotiated Discount $^{1,3,4}$ \\
I received \% discount. (validated with company and observer data) \\
\hline Purchase Intention $^{1}$ \\
It is very likely that I buy this car in this dealership. $(1=$ not at all; $7=$ extremely)
\end{tabular}

Revenue Goal Importance (Jaworski \& MacInnis 1989) ${ }^{2}(1=$ not at all; 7 = extremely)

If I do not meet my monthly revenue goals that is very bad for me.

If I do not meet my monthly revenue goals that is very bad for my financial situation.

If I do not meet my monthly revenue goals that is very bad for my job.

If I do not meet my monthly revenue goals that is very bad for my reputation among my colleagues.

Customer Orientation (Thomas, Soutar \& Ryan 2001) ${ }^{1}(1=$ not at all; 7 = extremely)

The salesperson has taken a problem solving approach in selling products or services to me.

The salesperson had my best interests in mind.

The salesperson has recommended products or services to me that are best suited to solve my problems.

\section{CPI Sensing Cues}

Customer Age $^{1}$

Your age:

Customer Product Knowledge (Wagner, Klein \& Keith 2001) ${ }^{1}$

I understand the features of cars enough to be considered an expert when evaluating different brands.

I know exactly what product characteristics are needed when buying a car.

If a friend of mine were buying a car, I would be an excellent source of information.

Relationship length (Bell, Auh \& Smalley 2005) ${ }^{1,2}$

For how long do you know the salesperson (customer)? years

\section{Controls}

\section{Encounter Length ${ }^{1}$}

How long did the encounter last? minutes

Salesperson's Experience (Levy \& Sharma 1994) ${ }^{2}$

For how many years have you been working as a salesperson? years

\section{Product Price Level $^{1}$}

What do you think is the average price one has to pay for this car? $€$

${ }^{1}$ Customer Data; ${ }^{2}$ Salesperson Data; ${ }^{3}$ Observer Data; ${ }^{4}$ Company Data

$\mathrm{CR}=$ Composite Reliability; AVE = Average Variance Extracted 